\title{
ANATOMIA FoliaR e CAULINAR DE Chamaecrista trichopoda (CAESALPINIOIDEAE) E HISTOQUímICA do NeCTÁRIO EXTRAFLORAL ${ }^{1}$
}

\author{
Foliar and Stem Anatomy of Chamaecrista trichopoda (Caesalpinioideae) and Extrafloral \\ Nectary Histochemistry
}

\author{
FRANCINO, D.M.T. ${ }^{2}$, SANT'ANNA-SANTOS, B.F. ${ }^{3}$, SILVA, K.L.F. ${ }^{4}$, THADEO, M. ${ }^{5}$, \\ MEIRA, R.M.S.A. ${ }^{6}$ e AZEVEDO, A.A. ${ }^{6}$
}

\begin{abstract}
RESUMO - Nectários são comuns dentre as Leguminosae, estando freqüentemente localizados nas folhas. Objetivou-se caracterizar anatomicamente o caule, a folha e o nectário extrafloral de Chamaecrista trichopoda, bem como investigar a natureza química do secretado do nectário dessa espécie. As amostras foram submetidas a testes histoquímicos e técnicas usuais em anatomia vegetal, sendo analisadas ao microscópio de luz e eletrônico de varredura. Os folíolos são anfiestomáticos e dorsiventrais, apresentando feixes vasculares colaterais com fibras associadas. Nas células da bainha do feixe é comum a ocorrência de monocristais. Tricomas tectores unisseriados e multicelulares ocorrem na lâmina foliar e no caule. O caule apresenta epiderme unisseriada, com três a quatro camadas de colênquima subepidérmico, seguido internamente por duas a três camadas de colênquima. Na camada mais interna do córtex destacam-se idioblastos cristalíferos contendo monocristais, o feixe vascular é delimitado por fibras e a medula é parenquimática. As características anatômicas foliares e caulinares corroboram os dados existentes para a subfamília Caesalpinioideae. O nectário situa-se na parte adaxial do pecíolo e apresenta coloração alaranjada, com o ápice formando uma concavidade, bordas levemente abauladas e pedúnculo com cerca de $1 \mathrm{~mm}$ de altura. É comum a ocorrência de pequenas aberturas na superfície do nectário e hifas fúngicas na fase póssecretora. Anatomicamente, confirmou-se uma estrutura semelhante à de um nectário, o qual é vascularizado por floema e xilema; o parênquima nectarífero ocorre abaixo da epiderme que apresenta cutícula espessa. Caracteres anatômicos do nectário podem auxiliar na taxonomia do gênero. As análises histoquímicas evidenciaram o acúmulo de tanino nas células do parênquima nectarífero, que pode funcionar como uma proteção à herbivoria. Observou-se a presença de poros na superfície do nectário, que podem ser sítios preferenciais de eliminação do néctar. Entretanto, futuras análises ao microscópio eletrônico de transmissão serão fundamentais para elucidar o processo de eliminação do néctar.
\end{abstract}

Palavras-chave: anatomia vegetal, Leguminosae, nectário extrafloral.

ABSTRACT - Nectaries are common among the Leguminosae, being frequently located in the leaves. The aim of this work was to anatomically characterize the stem, leaf and extrafloral nectary of Chamaecrista trichopoda, as well as to histochemically investigate the composition of the nectary secretion of this species. The samples were submitted to histochemical tests and usual plant anatomy techniques and analyzed through light microscope and scanning electron microscope. The leaflets are amphistomatic, dorsiventral, with collateral bundles and present associated fibers. It is common the occurrence of monocrystals in the bundle sheath cells. Uniseriate and multicellular tector trichomes occur in foliar lamina and stem. The stem presents uniseriate epidermis. Below the epidermis, three to four layers of collenchyma are observed, followed by two to three layers of chlorenchyma. In the most internal layers of the cortex,

Recebido para publicação em 17.5.2006 e na forma revisada em 10.11.2006.

Trabalho financiado pelo CNPq (Processo 476870/2006-2).

2 Mestranda em Botânica pela Universidade Federal de Viçosa - UFV, 36570-000 Viçosa-MG; ${ }^{3}$ Bolsista CAPES, Doutorando em Botânica pela UFV, <brunoufv@ yahoo.com.br>. ${ }^{4}$ Professora do Centro Universitário do Leste de Minas Gerais - UNILESTE-MG, 35160-215 Ipatinga-MG e Doutoranda em Botânica pela UFV; ${ }^{5}$ Bolsista CAPES, Doutoranda em Botânica pela UFV; ${ }^{6}$ Professor Adjunto, Departamento de Biologia Vegetal - DBV/UFV. 
crystalliferous idioblasts containing monocrystals are observed, and the bundle sheath is delimited by fibers and the pith is parenchymatic. The leaf and stem anatomy characteristics corroborate with the existing Caesalpinioideae subfamily data. The nectary is pedunculate, around $1 \mathrm{~mm}$ high and located in the adaxial part of the petiole, presenting an orange-like color, with the apex forming a concavity and the borders slightly rounded. It is common the occurrence of small openings on the surface of the nectary and fungi hyphae in the post-secretory phase. Anatomically, a nectary structure was confirmed. The nectary is vascularized by phloem and xylem with the nectariferous parenchyma occurring below the epidermis, which presents a thick cuticle. Anatomic characters may help study genus taxonomy. Histochemical analyses evidence the accumulation of tannins in the cells of the nectariferous parenchyma, likely functioning as a protection against herbivore. It was observed on the nectary surface the presence of pores, which may be preferential sites of nectar elimination. However, further analyses using transmission electronic microscope are fundamental to elucidate the process of nectar elimination.

Keywords: extrafloral nectary, Leguminosae, plant anatomy.

\section{INTRODUÇÃO}

O gênero Chamaecrista está incluído na subfamília Caesalpinioideae, família Leguminosae (Barroso et al., 1991; Herendeen, 2000), e compreende seis seções com 265 espécies, das quais 239 são nativas do continente americano (Irwin \& Barneby, 1982). O gênero tem distribuição pantropical (Irwin \& Barneby, 1981), sendo as regiões leste e centro-oeste do Brasil o centro de diversidade, onde é representado por aproximadamente 232 espécies (Irwin \& Barneby, 1982; Conceição et al., 2003).

Chamaecrista trichopoda ocorre no Brasil, Bolívia, Venezuela e Colômbia, sendo aqui encontrada nos estados de Goiás, Mato Grosso, Minas Gerais e São Paulo, estendendo-se até o Pará e Maranhão (Irwin \& Barneby, 1982). Ocorrendo em campos, pastagens e margens de matas (Irwin \& Barneby, 1982), C. trichopoda possui porte herbáceo, com cerca de $50 \mathrm{~cm}$ de altura, folíolo com margem inteira, faces adaxial e abaxial seríceas ou glabras, e uma estrutura no pecíolo de formato pateliforme estipitado, denominada de NEF (nectário extrafloral) (Dutra, 2005). Os NEFs são comuns dentre as espécies da família Leguminosae, estando freqüentemente localizados nas folhas, predominantemente na superfície adaxial do pecíolo ou na raque, entre os pares de folíolos (Elias, 1983).

Os nectários podem ser classificados, conforme a sua posição, sendo florais, aqueles presentes em peças florais, e extraflorais, em órgãos não-reprodutivos (Schmid, 1988). Os nectários florais geralmente estão envolvidos com estratégias de polinização (Janzen, 1966; Oliveira, 1997); entretanto, existem exceções, como no caso de Acacia terminalis, cujo nectário extrafloral disponibiliza recurso para o principal polinizador da espécie (Knox et al., 1985). Analogamente, essas estruturas podem estar envolvidas com a proteção das plantas contra o ataque de herbívoros e patógenos (Leitão et al., 2002; Leitão et al., 2005).

Os NEFs, para alguns taxa, são caracteres conservativos de valor unificador, úteis na delimitação genérica, como em Bignoniaceae (Seibert, 1948). Em outros casos, são caracteres distintivos, de valor diagnóstico, como em Leguminosae, onde podem ser úteis na distinção de espécies e variedades dos gêneros Cassia (Bhattacharyya \& Maheshwari, 1971a) e Chamaecrista (Dutra, 2005). A ocorrência, a localização e a estrutura anatômica dos nectários extraflorais em Cassia são consideradas bons caracteres taxonômicos para o gênero (Bhattacharyya \& Maheshwari, 1971a, b). Em outras abordagens, a caracterização de nectários extraflorais tem sido fundamental para estudos da interação inseto-planta, especialmente visando estabelecer estratégias de biocontrole de pragas em diversas lavouras (Bentley, 1983).

Nem sempre estruturas denominadas de NEFs, devido à observação dos caracteres externos, são confirmadas, pois há relatos de estruturas morfologicamente semelhantes às dos NEFs que, entretanto, secretam substâncias não-nectaríferas, como no caso de hidatódios em Impatiens (Elias \& Gelband, 1977) e glândulas de resina em Passiflora foetida 
(Durkee, 1982) e Populus grandidentata (Curtis \& Lersten, 1978).

Existem relatos da ocorrência de NEFs na subfamília Caesalpinioideae (Cowan, 1981), principalmente em gêneros tropicais (Bhattacharyya \& Maheshwari, 1971b). Muitos trabalhos realizados com representantes de Caesalpinioideae denominam estruturas de NEFs com base somente no seu aspecto externo (Conceição et al., 2003; Dutra, 2005); contudo, não foram realizadas avaliações anatômicas nem histoquímicas que pudessem confirmar a natureza dessas estruturas. Apesar de ser possível verificar a presença de açúcares solúveis no exsudado que asseguraria a classificação da estrutura como NEF, nem sempre esse procedimento é possível, principalmente nos casos dos estudos taxonômicos, que se baseiam em análises de exsicatas.

Objetivou-se caracterizar anatômica e histoquimicamente a estrutura presente no pecíolo de C. trichopoda, registrada na literatura taxonômica como nectário extrafloral, bem como descrever a anatomia do caule e da folha da espécie.

\section{MATERIAL E MÉTODOS}

Foram coletadas amostras de caule, folhas e nectários extraflorais (NEFs) de 10 indivíduos de Chamaecrista trichopoda (Leguminosae/ Caesalpinioideae). As plantas apresentavam cerca de $50 \mathrm{~cm}$ de altura, sendo provenientes de um campo situado na Universidade Federal de Viçosa (UFV), Minas Gerais. Material testemunho foi depositado no Herbário da UFV (VIC 29638).

\section{Microscopia eletrônica de varredura}

Amostras de partes de pecíolos contendo NEFs de cinco plantas foram fixadas em solução contendo glutaraldeído $(2,5 \%)$ e paraformaldeído (4\%) em tampão fosfato $0,1 \mathrm{M}$ pH 7,3 (Karnovsky, 1965) e pós-fixadas em tetróxido de ósmio (1\%). Após desidratação em série etílica, o material foi seco ao ponto crítico em equipamento Bal-Tec (modelo CPD 020, Bal-Tec, Balzers, Liechtenstein), utilizando $\mathrm{CO}_{2}$. Os fragmentos foram cobertos com ouro em metalizador (modelo FDU 010, Bal-Tec, Balzers, Liechtenstein) e a captura de imagens foi realizada em microscópio eletrônico de varredura com câmera digital acoplada (modelo Zeiss DSM 940A, Zeiss, Cambridge, England).

\section{Microscopia de luz}

Foram coletados segmentos de caule da porção apical entre o segundo e o terceiro nó a partir da gema apical, folhas totalmente expandidas e NEFs provenientes do quarto e quinto nós de cinco indivíduos diferentes. As amostras foram fixadas em $\mathrm{FAA}_{50}$ (Johansen, 1940) e estocadas em etanol $70 \%$.

Após desidratação em série etílica, os fragmentos foram incluídos em metacrilato (Historesina, Leica, Heidelberg, Alemanha) e os blocos cortados em micrótomo rotativo de avanço automático (modelo RM2155, Leica Microsystems Inc., Deerfield, USA). Secções transversais (pecíolos contendo NEFs, lâmina foliar e caule) e longitudinais (caule), com 6 a $9 \mu \mathrm{m}$ de espessura, foram coradas com Azul de Toluidina pH 4,0 (O’Brien \& McCully, 1981), para caracterização estrutural. Secções dos NEFs também foram submetidas à reação com PAS - Ácido Periódico/Reagente de Schiff (McManus, 1948), para detecção de polissacarídeos neutros. As lâminas foram montadas em Permount.

Para análise histoquímica foram coletadas amostras de folhas em diferentes estádios de desenvolvimento, desde jovens até totalmente expandidas, onde os NEFs apresentavam coloração alaranjada. Essas coletas foram realizadas de março a maio de 2005 , período em que as plantas apresentavam-se floridas. Amostras frescas de pecíolos contendo NEFs foram seccionadas à mão livre e os cortes longitudinais dos nectários foram montados em água glicerinada. As secções-controle foram realizadas simultaneamente aos testes histoquímicos, utilizando-se os procedimentos indicados na literatura pertinente (Tabela 1).

Para avaliação da epiderme em vista frontal foram realizadas diafanizações, segundo metodologia proposta por Kraus \& Arduin (1997), e impressões epidérmicas das superfícies adaxial e abaxial, conforme metodologia proposta por Rodella et al. (1983), utilizandose quatro folíolos em cada amostragem. Após 
secagem, a folha foi extraída com o auxílio de uma pinça, permanecendo sobre a lâmina a impressão epidérmica. Aleatoriamente, 10 imagens de cada folíolo foram capturadas e utilizadas para o cálculo do índice estomático de acordo com Cutter (1978), conforme a fórmula: $\mathrm{SI}=\left[\left(\mathrm{n}^{\circ}\right.\right.$ estômatos $/ \mathrm{n}^{\circ}$ estômatos $+\mathrm{n}^{\mathrm{o}}$ células epidérmicas) X 100]. Os dados foram submetidos à análise de variância em nível de $5 \%$ de probabilidade.

Tabela 1 - Testes histoquímicos aplicados para detecção das principais classes de metabólitos

\begin{tabular}{|c|c|c|}
\hline \multicolumn{2}{|c|}{ Grupos de Metabólitos } & $\begin{array}{c}\text { Reagente/Referência } \\
\text { Bibliográfica }\end{array}$ \\
\hline Lipídios & Lipídios totais & $\begin{array}{c}\text { Sudan Vermelho Escarlate } \\
\text { (Pearse, 1980) }\end{array}$ \\
\hline \multirow{2}{*}{$\begin{array}{c}\text { Compostos } \\
\text { fenólicos }\end{array}$} & $\begin{array}{c}\text { Compostos } \\
\text { fenólicos gerais }\end{array}$ & $\begin{array}{c}\text { Dicromato de Potássio } \\
\text { (Gabe, 1968) }\end{array}$ \\
\cline { 2 - 3 } & Taninos & $\begin{array}{c}\text { Vanilina Clorídrica } \\
\text { (Mace \& Howell, 1974) }\end{array}$ \\
\cline { 2 - 4 } Alcalóides & Lignina & $\begin{array}{c}\text { Floroglucinol } \\
\text { (Johansen, 1940) }\end{array}$ \\
\hline \multirow{2}{*}{ Glicídios } & Amido & $\begin{array}{c}\text { Reagente de Wagner } \\
\text { (Furr \& Mahlberg, 1981) }\end{array}$ \\
\cline { 2 - 3 } & Pectinas & $\begin{array}{c}\text { Vugol (Jensen, 1962) } \\
\text { (Johelho de Rutênio }\end{array}$ \\
\hline
\end{tabular}

A análise do material, a captura de imagens e a documentação fotográfica foram realizadas em um microscópio de luz (modelo AX70TRF, Olympus Optical, Tokyo, Japão) equipado com sistema U-Photo e com câmera digital acoplada (modelo Spot Insightcolour 3.2.0, Diagnostic instruments inc., New York, USA).

\section{RESULTADOS E DISCUSSÃO}

\section{Caracterização anatômica}

Os folíolos de Chamaecrista trichopoda possuem epiderme unisseriada e são anfiestomáticos (Figura 1A), apresentando maior índice estomático na face abaxial $(27,26 \%)$ do que na adaxial (15,38\%). Essa característica é comumente observada em membros de Caesalpinioideae (Solereder, 1908; Cowan, 1981; Watson, 1981). Os estômatos apresentam células subsidiárias em nível acima das células-guarda (Figura 1A, B) e são, predominantemente, do tipo paracítico (Figura 1C, D, E). As paredes anticlinais das células epidérmicas são sinuosas em ambas as faces das folhas (Figura 1D, E). Tricomas tectores multicelulares e unisseriados podem ser observados por toda a lâmina foliar (Figura 1F). A presença de tricomas na superfície foliar pode proporcionar redução da temperatura e, ainda, maior reflexão da radiação solar (Sousa, 1997; Ferreira, 2002).

O mesofilo é dorsiventral e compactamente arranjado, com uma camada de parênquima paliçádico ocupando mais da metade da espessura do mesofilo e três a quatro camadas de parênquima lacunoso (Figura 1A). Folhas dorsiventrais são comuns na subfamília Caesalpinioideae (Watson, 1981; Rezende et al., 1994). Como C. trichopoda se desenvolve com muita facilidade em locais com elevada incidência luminosa, a presença de tricomas e o mesofilo dorsiventral compacto podem atuar como importante estratégia adaptativa.

O sistema vascular é composto por feixe colateral com calotas de fibras associadas (Figura 1A). Células da bainha do feixe vascular contêm monocristais em seu conteúdo (Figura 1A, F, G).

O caule apresenta secção transversal circular, epiderme unisseriada e tricomas unisseriados e multicelulares com cutícula espessa (Figura 2A). Abaixo da epiderme observam-se de três a quatro camadas de colênquima anular (Figura 2A, B) e de duas a três camadas de parênquima clorofiliano (Figura 2A). A camada mais interna do córtex é formada por idioblastos cristalíferos contendo monocristais (Figura 2C, D, E, F). O sistema vascular é composto por 10 feixes, delimitados externamente por fibras (Figura 2C). Características como presença de cristais prismáticos e fibras encontradas no caule de C. trichopoda são citadas como freqüentes na subfamília (Solereder, 1908; Watson, 1981). Já neste estádio de desenvolvimento, os câmbios interfascicular (Figura 2C) e fascicular (Figura 2D) são observados, indicando o início de crescimento secundário.

Na região mediana do pecíolo ocorre uma estrutura descrita por Dutra (2005) como 

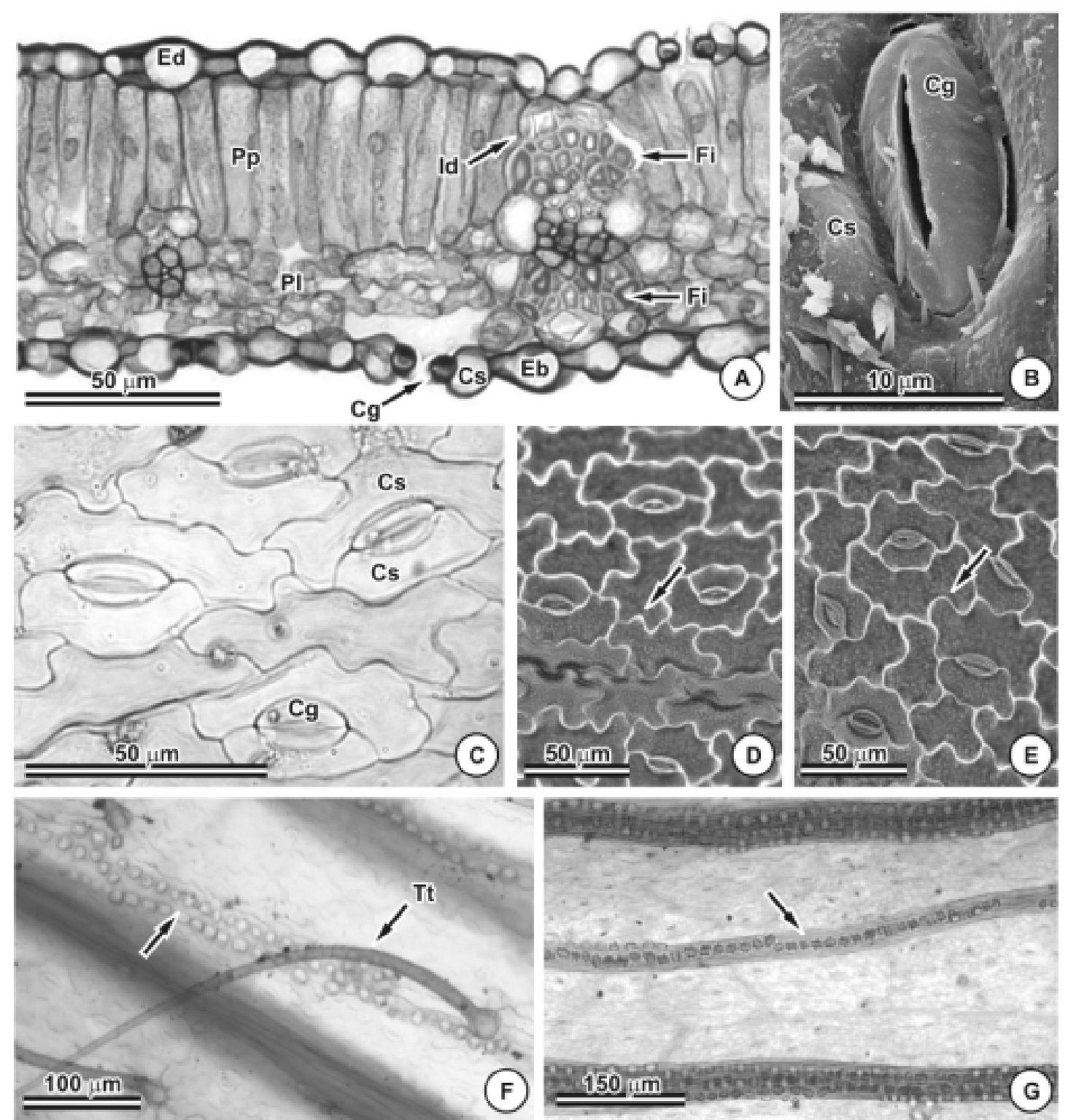

Figura 1 - Características anatômicas da folha de Chamaecrista trichopoda. A: secção transversal da folha. B: face abaxial da epiderme ao microscópio eletrônico de varredura, mostrando estômato. C: vista frontal do folíolo diafanizado - epiderme adaxial. D e E: sinuosidade das paredes anticlinais (seta) em impressão epidérmica das faces adaxial e abaxial da epiderme, respectivamente. F e G: epiderme adaxial em folíolo diafanizado - tricomas tectores (F) e bainha com monocristais (seta). Abreviaturas: Cg (célula-guarda), Cs (célula subsidiária), Eb (face abaxial da epiderme), Ed (face adaxial da epiderme), Fi (fibras), Id (idioblasto cristalífero), Pl (parênquima lacunoso), Pp (parênquima paliçádico) e Tt (tricoma tector).

sendo um nectário extrafloral pedunculado, com cerca de $1 \mathrm{~mm}$ de altura (Figura 3A), de coloração alaranjada (Figura 4D, E). Estruturas semelhantes foram relatadas para Cassia obtusifolia (Bhattacharyya \& Maheshwari, 1971a). Os nectários em folhas mais jovens se encontram em plena atividade, momento no qual a coloração alaranjada é evidente (Figura 4E), enquanto em folhas completamente diferenciadas encontram-se enegrecidos e aparentemente inativos. Segundo Metcalfe \& Chalk (1979), em alguns casos a atividade secretora dos NEFs é mais intensa nas folhas jovens. Essa distribuição 
temporal na atividade secretora é comumente observada em NEFs e também foi relatada em outros gêneros de Leguminosae (Elias, 1983; Paiva et al., 2001). Alguns caracteres, como posição, formato e coloração dos NEFs, possuem valor taxonômico em Leguminosae (Bhattacharyya \& Maheshwari, 1971a).

Na região da folha onde o nectário está inserido encontram-se inúmeros tricomas tectores (Figura 3B, C, D).

Ao microscópio eletrônico de varredura observa-se que a porção apical dos NEFs apresenta acúmulo de secretado na concavidade da região central (Figura 3B, E) e hifas fúngicas na borda dos NEFs (Figura 3D, E). Paiva (2003) também observou a presença de hifas fúngicas nos NEFs de Hymenaea stigonocarpa em fase pós-secretora.

Anatomicamente, os NEFs de C. trichopoda apresentam extensões de xilema e floema alcançando a zona secretora (Figura 4A, B, H). A presença de xilema e floema em nectários já foi relatada em outros gêneros de Caesalpinioideae (Bhattacharyya \& Maheshwari, 1971a; Paiva, 2003). O nectário de C. trichopoda possui epiderme unisseriada e cutícula espessa (Figura 4C). Observam-se três zonas distintas: zona secretora, localizada abaixo da epiderme, com cerca de oito camadas de células poligonais de parede fina e citoplasma denso, denominada parênquima nectarífero (Figura 4A, B); zona com duas a três camadas de células com parede espessa e citoplasma escasso; e zona vascular (Figura 4A), composta por xilema e floema (Figura 4B, H), de acordo com a descrição de Bhattacharyya \& Maheshwari (1971a) para a subfamília Caesalpinioideae, confirmando, dessa forma, que essas estruturas possuem semelhança anatômica com o que já foi descrito para nectários extraflorais.

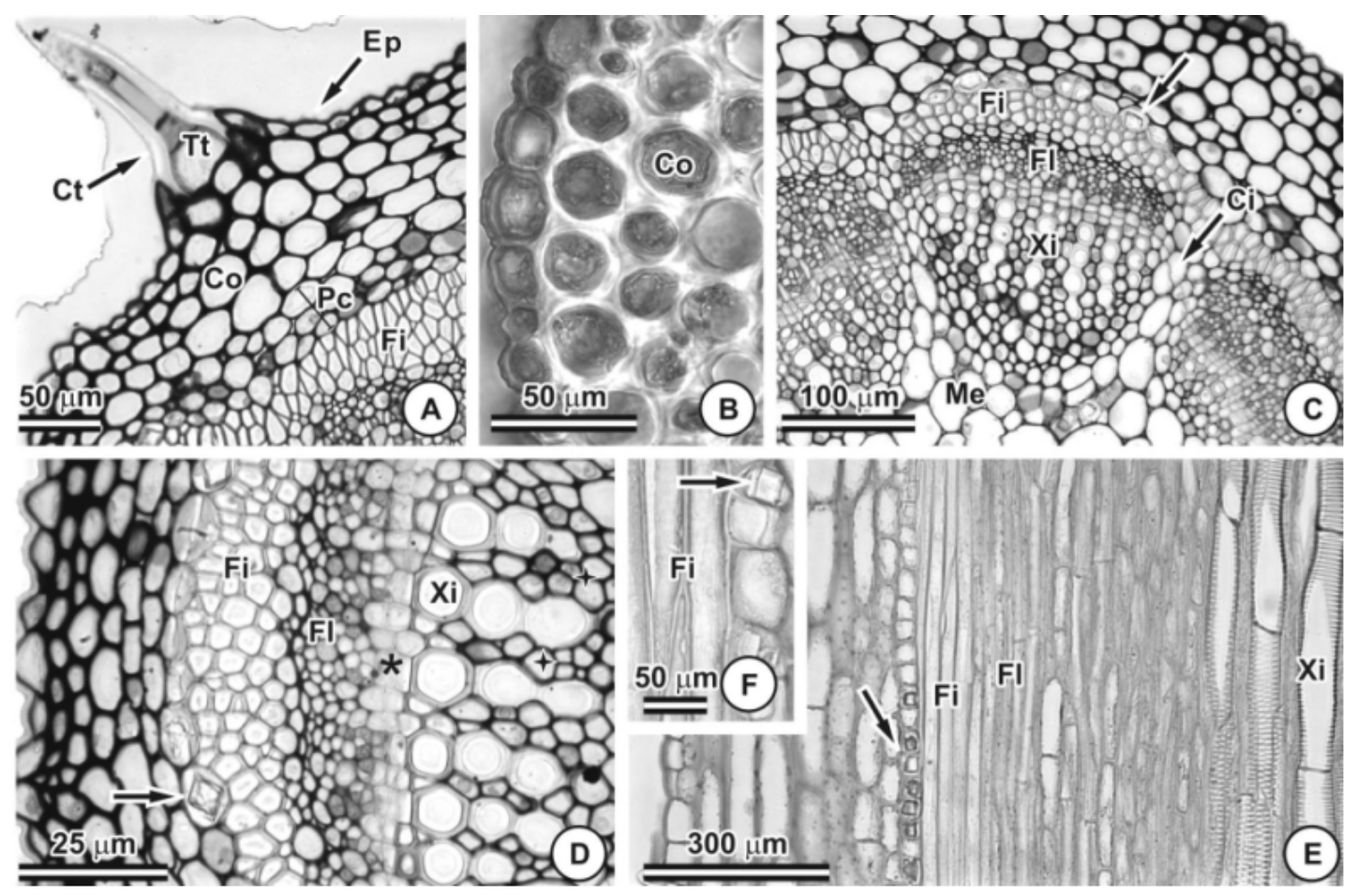

Figura 2 - Estrutura do caule de Chamaecrista trichopoda. A - D: cortes transversais. E e F: cortes longitudinais. A: tricoma tector multicelular e unisseriado. B: colênquima anular. C: monocristal (seta) na região mais interna do córtex. D: monocristal (seta), procâmbio (asterisco) e raios parenquimáticos (estrelas). E: bainha cristalífera (seta). F: monocristal (seta). Abreviaturas: Co (colênquima), Ci (câmbio interfascicular), Ct (cutícula), Ep (epiderme), Fl (floema), Fi (fibras), Me (medula), Pc (parênquima clorofiliano), Tt (tricoma tector) e Xi (xilema). 

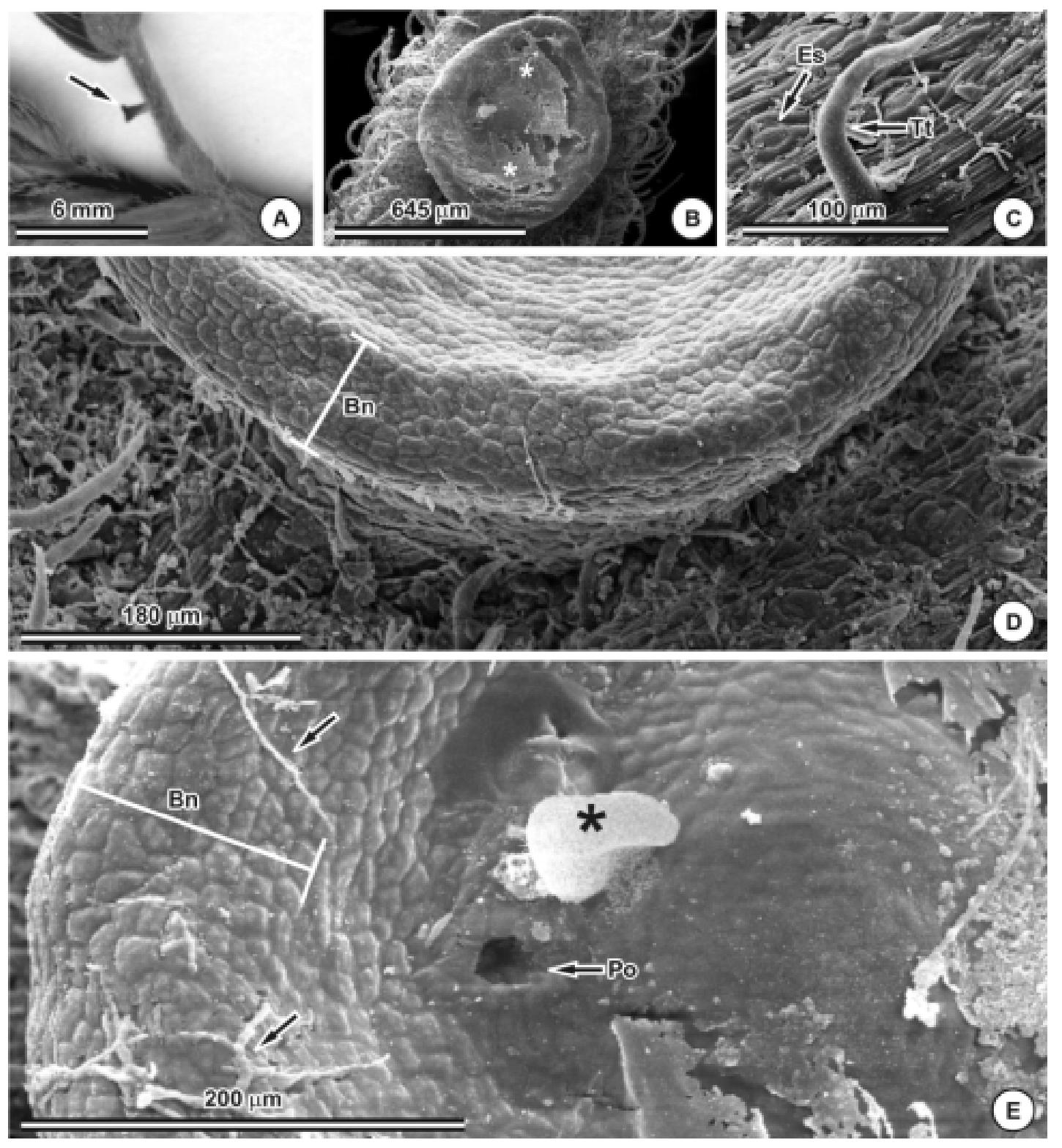

Figura 3 - Nectários extraflorais do pecíolo de Chamaecrista trichopoda. A - E: aspecto morfológico. A: nectário situado na face adaxial do pecíolo (seta). B - E: fotomicrografias eletrônicas de varredura. B: acúmulo de secretado na região central (asteriscos). C: tricoma tector no pecíolo. D: vista frontal do nectário. E: poro, acúmulo de secretado (asterisco) e hifas fúngicas na borda (setas). Abreviaturas: Bn (borda do nectário), Es (estômato), Po (poro) e Tt (tricoma tector).

\section{Análise histoquímica}

Na caracterização histoquímica dos NEFs de C. trichopoda (Tabela 2), a reação negativa ao sudan escarlate descarta a possibilidade da presença de compostos lipofílicos. O teste com lugol detectou amido na região cortical do pecíolo (Figura 4F), que apresenta o sistema vascular constituído por um feixe central e dois acessórios, todos envolvidos por uma calota de fibras, evidenciadas pelo floroglucinol (Figura 4D, G, H). No presente estudo observou-se que a vascularização dos NEFs provém do feixe vascular principal do pecíolo (Figura $5 \mathrm{D}$ ), que, ao se bifurcar para o $\mathrm{NEF}$, não se encontra acompanhado pela calota de fibras. 

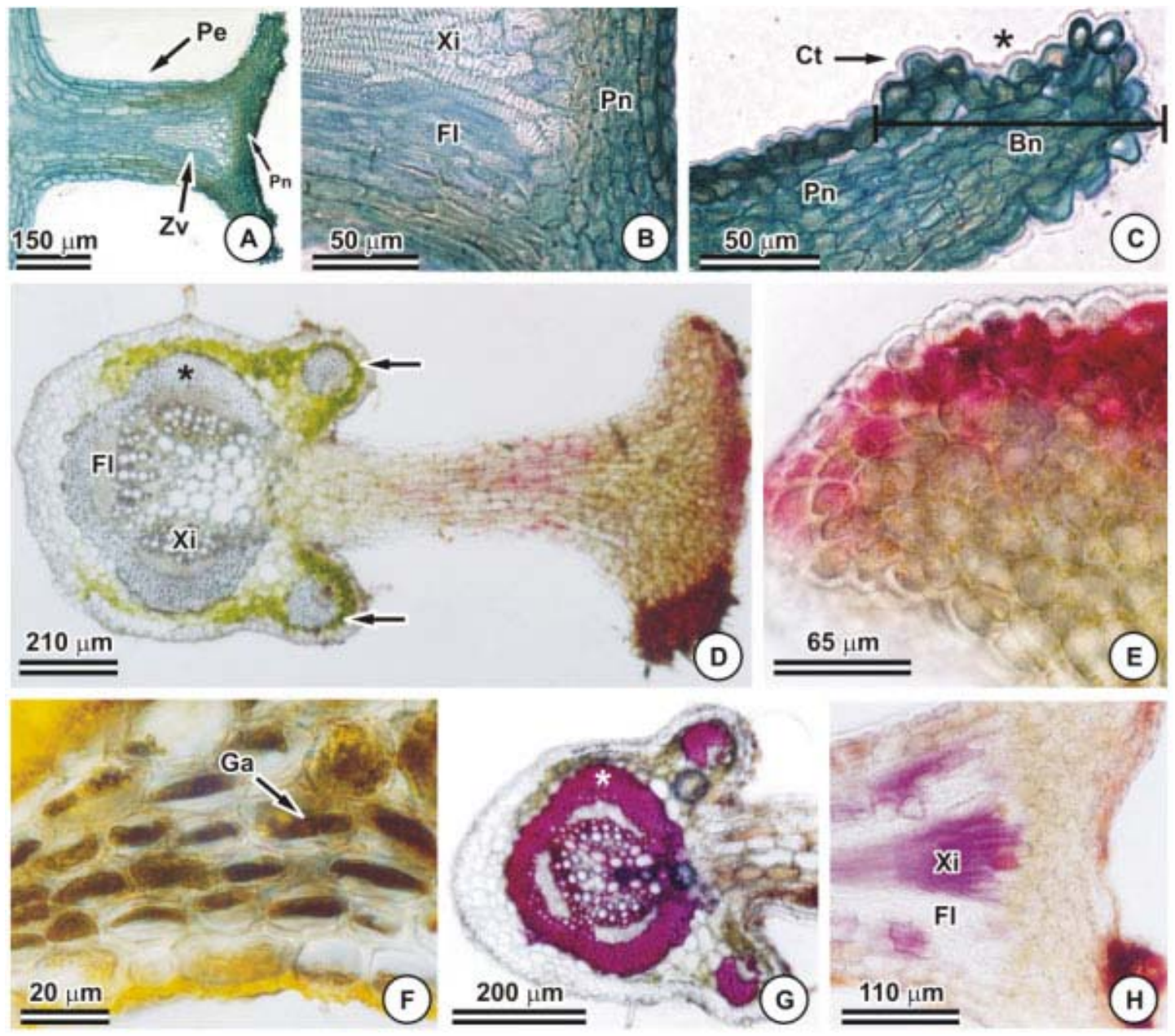

Figura 4 - Aspecto anatômico, em microscopia de luz, do nectário extrafloral de Chamaecrista trichopoda (cortes longitudinais do nectário e transversais do pecíolo). A - C: Azul de Toluidina A: zona vascular adjacente ao parênquima nectarífero. B: células do parênquima nectarífero e tecidos vasculares. C: borda levemente abaulada (asterisco). D e E: aspecto do nectário a fresco (branco). D: setas indicando feixes vasculares acessórios e asterisco mostrando fibras em arco ao redor do feixe no pecíolo. E: coloração alaranjada da zona secretora do nectário. F: teste com Lugol: presença de amido nas células corticais do pecíolo. G e H: Floroglucinol, mostrando lignificação na parede das fibras (asterisco) do pecíolo e no xilema do nectário. Abreviaturas: Bn (borda do nectário), Ct (cutícula), Fl (floema), Ga (amiloplastos repletos de grãos de amido), Pe (pedúnculo), Pn (parênquima nectarífero), Xi (xilema) e Zv (zona vascular).

Estrutura diferente foi relatada para NEF de Pithecellobium macradenium, onde o suplemento vascular provém dos feixes acessórios do pecíolo, sendo estes acompanhados pelas fibras (Elias, 1972).

O teste do vermelho de rutênio e o PAS não indicaram a presença de polissacarídeos nos NEFs (Tabela 2). O resultado negativo para polissacarídeos nos NEFs pode estar relacionado a uma seqüência cíclica da liberação de exsudados, comumente observada em nectários coletados após a fase secretora. Uma outra hipótese se refere à fenofase floral em que as plantas se encontravam, demandando maior energia para a produção de flores e frutos.

A reação positiva ao dicromato de potássio evidenciou compostos fenólicos (Figura 5A, B). Leitão et al. (2002) também observaram compostos fenólicos nos NEFs de Triumfetta semitriloba (Tiliaceae). Compostos fenólicos são 
Tabela 2 - Histoquímica do nectário extrafloral peciolar de Chamaecrista trichopoda

\begin{tabular}{|l|c|c|}
\hline Grupo de compostos & Teste & Nectário \\
\hline Lipídios Totais & Sudan Escarlate & - \\
\hline \multirow{3}{*}{ Compostos Fenólicos } & Dicromato de Potássio & + \\
\cline { 2 - 3 } & Vanilina Clorídrica & + \\
\cline { 2 - 3 } & Floroglucinol & + \\
\hline Alcalóides & Reagente de Wagner & - \\
\hline \multirow{3}{*}{ Glicídios } & PAS & - \\
& Lugol & - \\
\cline { 2 - 3 } & Vermelho de Rutênio & - \\
\hline
\end{tabular}

Abreviaturas: + (reação positiva); - (reação negativa).

substâncias adstringentes que promovem impalatabilidade para herbívoros e fitófagos, tendo grande importância funcional na interação de plantas com animais (Fahn, 1979; Roshchina \& Roshchina, 1993; Carvalho et al., 2000). A vanilina clorídrica especificou a natureza tanífera do conteúdo das células dos NEFs (Figura 5C), em comparação com o controle (Figura 5D). Células parenquimáticas associadas com as células secretoras de nectários vascularizados geralmente contêm grandes depósitos de tanino (Elias, 1983), como em
Leonardoxa africana (Elias, 1980). A ocorrência de tanino nos NEFs de Caesalpinioideae é comum (Bhattacharyya \& Maheshwari, 1971a).

Em geral, o néctar é exsudado do nectário através de células epidérmicas ordinárias, tricomas ou por células do parênquima nectarífero que secretam dentro de espaços intercelulares e, daí, para a superfície externa, por meio de estômatos modificados ou pela ruptura da cutícula (Fahn, 1979). Em várias das amostras analisadas, observou-se, em $C$. trichopoda, a presença de diminutos poros no centro da concavidade da superfície do NEF (Figura 3E), os quais aparentemente se constituem nos sítios preferenciais de eliminação do néctar; entretanto, análises ultra-estruturais são necessárias para se confirmar tal hipótese.

Os caracteres anatômicos observados no caule e na lâmina foliolar de C. trichopoda se assemelham aos descritos na literatura para outras espécies da subfamília Caesalpinioideae. Alguns caracteres referentes à vascularização, como interrupção das fibras no pecíolo e suplemento vascular do nectário proveniente do feixe principal, podem apresentar valor
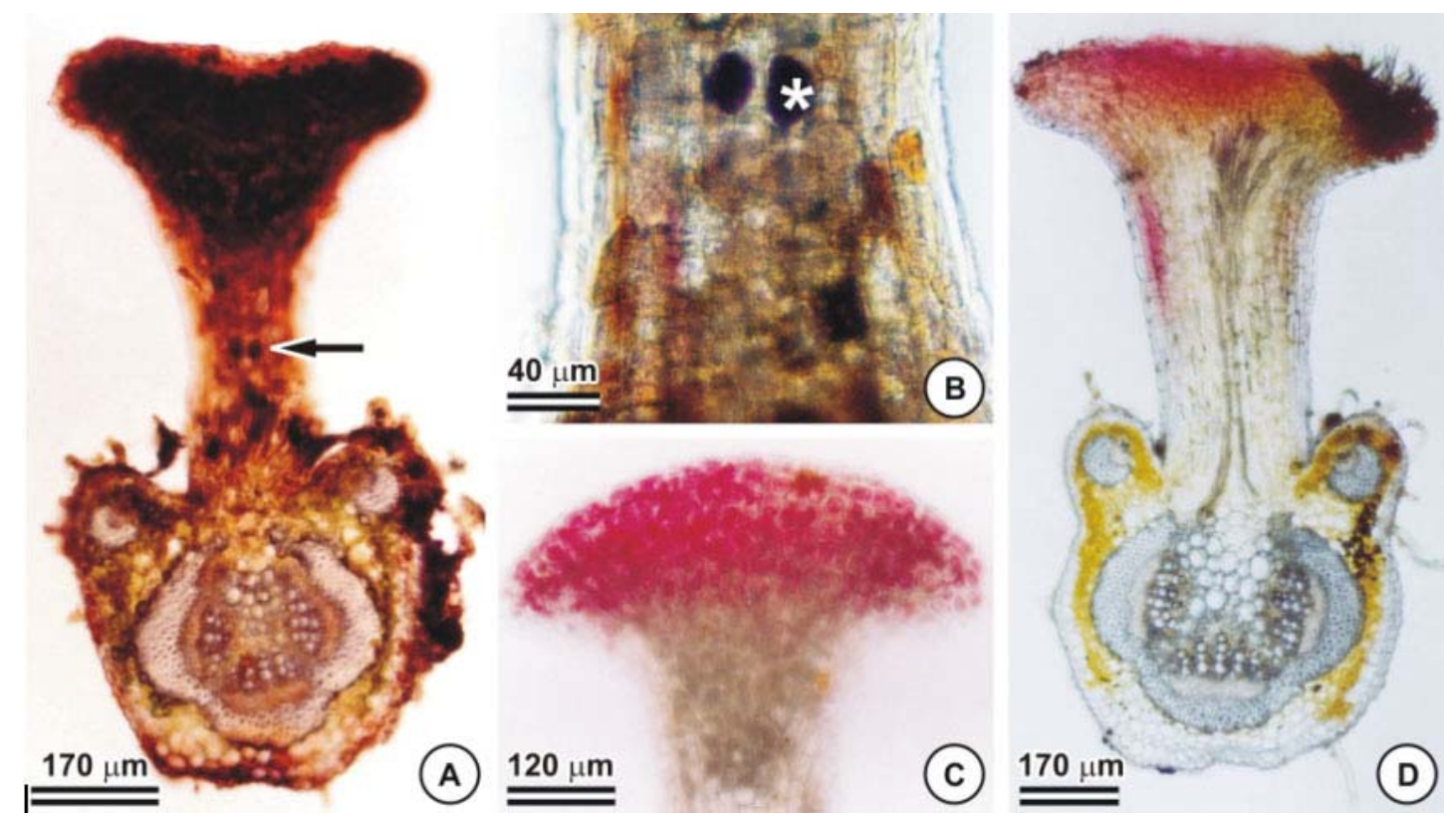

Figura 5 - Cortes longitudinais do nectário extrafloral de Chamaecrista trichopoda submetidos a testes histoquímicos. A e B: dicromato de potássio. A: visão geral do nectário, seta indicando local do detalhe (B). B: compostos fenólicos (asterisco) nas células do pedúnculo. C e D: vanilina clorídrica. C: tanino nas células do parênquima nectarífero. D: controle de C. 
diagnóstico, por serem de ocorrência restrita. O estudo anatômico de outras espécies do gênero Chamaecrista será fundamental para estabelecer melhor o valor taxonômico dos caracteres anatômicos observados.

Embora as estruturas secretoras presentes no pecíolo de $C$. trichopoda tenham sido denominadas de NEFs (Dutra, 2005), não foram encontradas referências quanto à sua caracterização estrutural. Considerando que existem relatos de estruturas morfologicamente semelhantes a nectários, como, por exemplo, hidatódios, glândulas de resina, coléteres (Fahn, 1979), o presente trabalho é relevante, pois confirma que anatomicamente tais estruturas podem ser classificadas como NEFs, pela presença de vascularização xilemática e floemática em proporções equivalentes. Contudo, a análise histoquímica não demonstrou a presença de açúcares no secretado.

Os dados histoquímicos obtidos registram pela primeira vez a natureza química do secretado dos nectários de C. trichopoda. A presença de taninos provavelmente confere aos NEFs de C. trichopoda proteção contra o ataque de herbívoros. A utilização, em futuras análises, da microscopia eletrônica de transmissão será fundamental para esclarecer o processo secretor de C. trichopoda.

\section{AGRADECIMENTOS}

Os autores agradecem ao Núcleo de Microscopia e Microanálise (UFV), ao professor Elliot Watanabe Kitajima (NAP/MEPA), à Vânia M. M. Valente e à Valquíria F. Dutra.

\section{LITERATURA CITADA}

BARROSO, G. M. et al. Sistemática de angiospermas do Brasil. Viçosa, MG: Imprensa Universitária, 1991. 377 p.

BENTLEY, B. L. Nectaries in agriculture, with an emphasis on the tropics. In: BENTLEY, B.; ELIAS, T. S. The biology of nectaries. New York: Columbia University Press, 1983. p. 204-222.

BHATTACHARYYA, B.; MAHESHWARI, J. K. Studies on extrafloral nectaries of the Leguminales - I. Papilionaceae, with a discussion on the systematics of the Leguminales. Proc. Indian Nat. Sci. Acad., B., v. 37, p. 11-30, 1971a.

BHATTACHARYYA, B.; MAHESHWARI, J. K. Studies on extrafloral nectaries of the Leguminales - II. The genus Cassia Linn. (Caesalpiniaceae). Proc. Indian Nat. Sci. Acad., B., v. 37, p. 74-90, 1971 b.
CARVALHO, J. C. T.; GOSMANN, G.; SCHENKEL, E. P. Compostos fenólicos simples e heterosídicos. In: SIMÕES, C. M. O. et al. (Eds.). Farmacognosia: da planta ao medicamento. Florianópolis: Universidade Federal do Rio Grande do Sul, 2000. p. 451-469.

CONCEIÇÃO, A. S.; GIULIETTI, A. M.; QUEIROZ, L. P. $\mathrm{O}$ gênero Chamaecrista Moench (LeguminosaeCaesalpinioideae) em Catolés, Abaíra, Chapada Diamantina, Bahia, Brasil. Sitientibus, Série Ci. Biol., v. 3, p. 81-108. 2003.

COWAN, R. S. Caesalpinioideae. In: POLHILL, R. M.; RAVEN, P. H. (Eds.). Advances in legume systematics part I. Kew: Royal Botanic Gardens, 1981. p. 57-64.

CURTIS, J. D.; LERSTEN, N. R. Heterophylly in Populus grandidentata (Salicaceae) with emphasis on resin glands and extrafloral nectaries. Am. J. Bot., v. 65, p. 1003-1010, 1978.

CUTTER, E. G. Plant anatomy: cells and tissues. Part I. London: William Clowes and Sons, 1978. 315 p.

DURKEE, L. T. The floral and extra-floral nectaries of Passiflora. II. The extra-floral nectary. Am. J. Bot., v. 69, p. 1420-1428, 1982.

DUTRA, V. F. Leguminosae Adans, nos campos rupestres do Parque Estadual do Itacolomi, Minas Gerais, Brasil: florística, preferência por hábitat, aspectos reprodutivos e distribuição geográfica. 2005. 189 f. Dissertação (Mestrado em Botânica) - Universidade Federal de Viçosa, Viçosa,MG, 2005.

ELIAS, T. S. Extrafloral nectaries - their structure and distribution. In: BENTLEY, B.; ELIAS, T. S. The biology of nectaries. New York: Columbia University Press, 1983. p. 174-203.

ELIAS, T. S. Foliar nectaries of unusual structure in Leonardoxa africana (Leguminosae), an african obligate myrmecophyte. Am. J. Bot., v. 67, p. 423-425, 1980.

ELIAS, T. S. Morphology and anatomy of foliar nectaries of Pithecellobium macradenium (Leguminosae). Bot. Gaz., v. 133, p. 38-42, 1972.

ELIAS, T. S.; GELBAND, H. Morphology, anatomy, and relationship of extrafloral nectaries and hidathodes in two species of Impatiens (Balsaminaceae). Bot. Gaz., v. 138, p.206-212, 1977.

FAHN, A. Ultrastructure of nectaries in relation to nectar secretion. Am. J. Bot., v. 66, p. 977-985, 1979.

FERREIRA, K. M. Comparações morfo-anatômicas e químicas entre populações de Marcetia taxifolia (St. Hill) DC. (Melastomataceae) nos campos rupestres da Serra do Cipó-MG. 2002. 73 f. Dissertação (Mestrado em Botânica) - Universidade Federal de Viçosa, Viçosa, MG, 2002. 
FURR, M.; MAHLBERG, P. G. Histochemical analyses of lacticifers and glandular trichomes in Cannabis sativa. J. Nat. Prod., v. 44, p. 153-159, 1981.

GABE, M. Techniques histologiques. Paris: Masson \& Cie, 1968. $1113 \mathrm{p}$

HERENDEEN. P. S. Structural evolution in the Caesalpinioideae (Leguminosae). In: HERENDEEN, P. S.; BRUNEAE, A. Advances in legume systematics 9. Kew: Royal Botanic Gardens, 2000. p. 45-64.

IRWIN, H. S.; BARNEBY, R. C. Cassieae. In: POLHILL, R. M.; RAVEN, P. H. Advances in legume systematics part I. Kew: Royal Botanic Gardens, 1981. p. 97-106.

IRWIN, H. S.; BARNEBY, R. C. The American Cassinae - A synoptical revision of Leguminosae - Tribe Cassieae subtribe Cassiinae in the New World. Mem. New York Bot. Gard., v. 35, p. 1-918, 1982.

JANZEN, D. H. Coevolution of mutualism between ants and acacias in Central America. Evolution, v. 20, p. 249-275, 1966.

JENSEN, W. A. Botanical histochemistry: principles and practice. San Francisco: WH Freeman, 1962. 408 p.

JOHANSEN, D. A. Plant microtechnique. New York: McGraw- Hill, 1940. 523 p.

KARNOVSKY, M. J. A formaldehyde-glutaraldehyde fixative of high osmolarity for use in electron microscopy. J. Cell Biol., v. 27, p. 137-138, 1965.

KNOX, R. B. et al. Extrafloral nectaries as adaptations for bird pollination in Acacia terminalis. Am. J. Bot., v. 72, p. 1185-1196, 1985.

KRAUS, J. E.; ARDUIN, M. Manual básico de métodos em morfologia vegetal. Seropédica: Universidade Federal Rural do Rio de Janeiro, 1997. 198 p.

LEITÃO, C. A. E. et al. Anatomy of the floral, bract, and foliar nectaries of Triumfetta semitriloba (Tiliaceae). Can. J. Bot., v. 83, p. 279-286, 2005.

LEITÃO, C. A. E. et al. Ontogenia dos nectários extraflorais de Triumfetta semitriloba (Tiliaceae). Planta Daninha, v. 20, p. 343-351, 2002.

MACE, M. E.; HOWELL, C. R. Histochemistry and identification of condensed tannin precursor in roots of cotton seedlings. Can. J. Bot., v. 52, p. 2423-2426, 1974.

McMANUS, J. F. A. Histological and histochemical uses of periodic acid. Stain Technol., v. 23, p. 99-108, 1948.

METCALFE, C. R.; CHALK, L. Anatomy of the dicotyledons. New York: Oxford University Press, 1979. v. $1.276 \mathrm{p}$.
O‘BRIEN, T. P.; McCULLY, M. E. The study of plant structure principles and select methods. Melbourne: Termarcarphi Pty, 1981. 45 p.

OLIVEIRA, P. S. The ecological function of the extrafloral nectaries: herbivore deterrence by visiting ants and reproductive output in Caryocar brasiliense (Caryocaraceae). Funct. Ecol., v. 11, p. 323-330, 1997.

PAIVA, E. A. S. Estruturas secretoras em Hymenaea stigonocarpa (Fabaceae-Caesalpinioideae): uma abordagem morfofuncional. 2003. $125 \mathrm{f}$. Tese (Doutorado em Ciências Biológicas) - Universidade Estadual Paulista, Botucatu, 2003.

PAIVA, E. A. S. et al. Occurence and structure of extrafloral nectaries in Pterodon pubescens Benth. and Pterodon polygalaeflorus Benth. Pesq. Agropec. Bras., v. 36, p. 219-224, 2001.

PEARSE, A. G. E. Histochemistry theoretical and applied: preparative and optical technology. 4.ed. Edinburgh: Churchill Livingston, 1980. 439 p.

REZENDE, M. H.; CARDOSO, L. A.; VANNUCCI, A. L. Morfologia e anatomia foliar de Bauhinia curvula Benth. (Leguminosae - Caesalpinioideae). Acta Bot. Bras., v. 8, p. 19-34, 1994.

RODELLA, R. A. et al. Anatomia comparativa foliar e caulinar de duas espécies daninhas de Merremia (Convolvulaceae). Científica, v. 21, p. 345-353, 1983.

ROSHCHINA, V. V.; ROSHCHINA, V. D. The excretory function of higher plants. Berlin: Springer-Verlag, 1993. $314 \mathrm{p}$.

SCHMID, R. Reprodutive versus extra-reprodutive nectaries - historical perspective and terminological recommendations. Bot. Rev., v. 54, p. 179-232, 1988.

SEIBERT, R. J. The use of gland in a taxonomic consideration of the family Bignoniaceae. Ann. Molec. Bot. Gard., v. 35, p. 123-136, 1948.

SOLEREDER, H. Systematic anatomy of the Dicotiledons. Oxford: Claredon Press, 1908. 1182 p.

SOUSA, H. C. Estudo comparativo de adaptações anatômicas em órgãos vegetativos de espécies de Lavoisiera DC. (Melastomataceae) da Serra do Cipó, MG. 1997. 185 f. Tese (Doutorado em Ciências Biológicas) Universidade de São Paulo, São Paulo, 1997.

WATSON, L. An automated system of generic description for Caesalpinioideae, and its application to classification and key-making. In: POLHILL, R. M.; RAVEN, P. H. Adv. Leg. Syst., v. 1, p. 65-80, 1981. 